\title{
VIEWING VERSUS LISTENING OF STORIES BY PAKISTANI CHILDREN FROM LOW SOCIO-ECONOMIC BACKGROUND - AN EXPERIMENTAL STUDY OF MEDIA EFFECTS ON COGNITION
}

\author{
Khushboo Rafiq* \\ Nisar Ahmed Zuberi**
}

\begin{abstract}
This research sets out to study and compare the effects of story watching on television and story listening by an elder on children's cognitive skills, specifically in building up their vocabulary and comprehension. A total of two hundred children aged between 7 to 12 years from low socio-economic background were selected through matching. They were divided into two different groups based on the medium they were exposed to, either oral or visual. The study took place in laboratories set at four different schools in Karachi, Pakistan. Ten stories were told to the half children, while the other group watched 10 animated episodes having same content for 10 consecutive weeks. Children's perception and vocabulary skills were evaluated through questionnaires, which were filled out after each story. Results affirmed the hypothesis that story listening is more effective than cartoon watching in terms of cognitive learning. The study is beneficial for various disciplines of social sciences including psychology, sociology, education and mass communication.
\end{abstract}

Keywords: Cartoon viewing; story listening; media effects; cognitive skills; vocabulary; perception; children

\section{Introduction}

Children and stories are considered to be closely associated. Many researchers support the idea to read from books and suggest that this activity ripens emotional bonding between parents and children and enhances communication skills. ${ }^{1}$ Storytelling started not days or years but centuries back. From Lascaux Caves of around 15,000 BC to the epic of Gilgamesh in $700 \mathrm{BC}$, the series of telling fables has remained alive throughout history. With the passage of time, oral storytelling got transformed into printed form, and then printed sources extended to digitized modes.

John Locke poised the idea of tabula rasa or "blank slate" in 1700s. He argued that the mind of a new-born child is like "a blank slate upon which experience writes". He

\footnotetext{
* Khushboo Rafiq, Lecturer, Department of Media and Communication Studies, Sindh Madressatul Islam University, Karachi.

*** Nisar Ahmed Zuberi, Ph.D. Adjunct Professor, Department of Mass Communication, University of Karachi, Karachi.

${ }^{1}$ Campbell, David E., and Toni A. Campbell. "Effects of live and recorded story telling on retelling performance of preschool children from low socioeconomic backgrounds." Psychology in the Schools (Indiana: Wiley-Blackwell, 1976) 201-204.
} 
focused on the nurturing aspect of development mainly provided by parents. Eighteenth century's philosopher Rousseau presented two core ideas about childhood development. Unlike Locke, he claimed that children are valuable and their psychology is different from adults. Later theorists like A.S. Neill, Arnold Gesell, Friedrich Froebel, Jean Piaget, Jerome Bruner, Johann Pestalozzi, Karen Horney, Lawrence Kohlberg, Maria Montessori etc. affirmed this idea.

Piaget (1936) is considered as one of the most influential theorists of the 20th century who contributed comprehensively on children's development stages. The latest version of the theory presented in 1958 defines five different stages of cognitive development. ${ }^{2}$ The third stage proposed by Piaget is denoted as "concrete operational stage". In this particular stage, the child develops the sense to interpret objects logically. ${ }^{3}$

Behavioural psychologists such as Watson and Skinner ${ }^{4}$ designated the environment more important tool in shaping humans' lives as compared to genes and biological factors. They supported the perspective of social learning and believed that operant and classical conditioning are mainly involved in the language learning process. It is a phenomenon that is gradually learned by repeatedly imitating what children listen and observe, mainly from their parents and surroundings. Skinner ${ }^{5}$ particularly put emphasis on the role of reinforcement. Correct usage of grammar and accurately uttered words are appreciated and rewarded by parents, so children tend to use them more often. In an experimental study on elementary school children, Stein and Glenn ${ }^{6}$ perused the story comprehension of narrative material by evaluating the recalling abilities of first and fifth grade students. Results indicated that primacy events were recalled more and fifth grade children performed better to recall stories correctly.

Vygotskian perspective shows that aspects of both nativist and behaviourist approaches are involved in the process of language development. ${ }^{7}$ Interactionists support the view that language is a product of environmental and biological factors. However, within the same theory, some theorists consider environmental aspects more significant such as interactions with parents, siblings and peers ${ }^{8}$ while others believe that biological elements are more important in determining language development. ${ }^{9}$

\footnotetext{
${ }^{2}$ Wadsworth, Barry J. "Piaget's theory of cognitive and affective development." (London: Longman Publishing, 2004) 62-75.

${ }^{3}$ Hurlock, Elizabeth B. "Developmental Psychology-A life span approach." (New Delhi: Tata McGraw Hill, 1981) $156-158$.

${ }^{4}$ Gresham, Frank M., T. Steuart Watson, and Christopher H. Skinner. "Functional behavioral assessment: Principles, procedures, and future direction." School Psychology Review (Columbia: National Association of School Psychologists, 2001) 156.

${ }^{5}$ Skinner, Burrhus Frederic. "What is the experimental analysis of behavior?." Journal of the Experimental Analysis of behavior (Utah: Wiley-Blackwell, 1966) 213-218.

${ }^{6}$ Stein, Nancy L., and Christine G. Glenn. "An Analysis of Story Comprehension in Elementary School Children: A Test of a Schema." (Washington DC: ERIC, 1975) 30-42.

${ }^{7}$ Astington, Janet Wilde, and Alison Gopnik. "Theoretical explanations of children's understanding of the mind." British Journal of Developmental Psychology (London, Wiley-Blackwell, 1991) 7-31.

${ }^{8}$ Meltzoff, Andrew N. "Origins of theory of mind, cognition and communication." Journal of communication disorders (Iowa: Elsevier, 1999) 251-269.

${ }^{9}$ Moerk, Ernst L. "Processes of language teaching and training in the interactions of mother-child dyads." Child Development (Medford: Wiley-Blackwell, 1976) 1064-1078.
} 
Storytelling, family therapy directive storytelling in particular, can be a very useful tool in solving children's disabilities particularly related to learning problems by revitalizing family bonding. ${ }^{10}$ Researchers such as Seay, Hansen and Harlow ${ }^{11}$ largely focused on the attachment and relationships in the process of development after World War II. Bowlby proclaimed that we are inclined towards caring and affectionate relationships by birth. Supporting Freud's psychoanalytic perspective, Bowlby highlighted the importance of early relationships in determining future behaviours and skills. ${ }^{12}$

\section{Studies on the Effects of Storytelling on Children's Perception}

Perhaps, people had started analysing the effects of narrations right after the language creation. Several studies have been transpired regarding the effects of stories in shaping children's personality, particularly their language skills development, vocabulary, reading and writing abilities, comprehension and learning outcomes. Most of the studies support the idea that storytelling enhances children's vocabulary and develops their language skills that have a large impact on their cognition.

When we talk about learning, several studies show that storytelling has an immense effect on children's vocabulary and language skills. Robbins and Ehri ${ }^{13}$ upheld the idea that story listening enhances vocabulary learning. They stressed that story listening practice was directly proportional to the understanding of new words. They also indicated the point that short term or long term memory slippage might be a critical determinant to examine vocabulary learning inference.

Children from ethnically different backgrounds in New Zealand were observed on weekly basis for three consecutive weeks by Penno et al. ${ }^{14}$. The both said studies reinforced the accumulative advantage by arguing that higher ability respondents acquired more words and correct vocabulary consumption as compared to lower ability subjects. Tompkins et al. ${ }^{15}$ reported a similar result like many previous studies while correlating inference making and narrative comprehension with each other. After their experimental study conducted on kindergartners, they reached on the conclusion that children's inferences and their story comprehension were highly interrelated. Kim and Phillips ${ }^{16}$ held a similar point of view by discussing the active and positive roles of

${ }^{10}$ Correa, Julio E., Olga B. González, and Martha S. Weber. "Story telling in families with children: a therapeutic approach to learning problems." Contemporary Family Therapy (New York: Human Sciences Press, 1991) 33-59.

${ }^{11}$ Seay B., Hansen E., and Harlow Harry F. "Mother-infant separation in monkeys." Journal of Child Psychology and Psychiatry (New York: Wiley-Blackwell, 1962) 123-132.

${ }^{12}$ Currie, Nicola Kate, and Kate Cain. "Children's inference generation: The role of vocabulary and working memory." Journal of Experimental Child Psychology (Florida: Elsevier, 2015) 57-75.

${ }^{13}$ Robbins, Claudia, and Linnea C. Ehri. "Reading storybooks to kindergartners helps them learn new vocabulary words." Journal of Educational psychology (Arizona: American Psychological Association, 1994) 54.

${ }^{14}$ Penno, Julie F., Ian AG Wilkinson, and Dennis W. Moore. "Vocabulary acquisition from teacher explanation and repeated listening to stories: Do they overcome the Matthew effect?." Journal of Educational Psychology (Arizona: American Psychological Association, 2002) 23.

${ }^{15}$ Tompkins, Virginia, Ying Guo, and Laura M. Justice. "Inference generation, story comprehension, and language skills in the preschool years." Reading and Writing (California: Springer, 2013) 403-429.

${ }^{16}$ Kim, Young-Suk, and Beth Phillips. "Cognitive correlates of listening comprehension." Reading Research Quarterly (New York: Wiley-Blackwell, 2014) 269-281. 
inhibitory control, theory of mind and perception monitoring in cognition of listening skills among the young children from low-income background.

From the discussed postulates, it can be said that perhaps story listening is one of the oldest form of communication that is creating impeccable effect on children's inference making and learning to date. However, there has been a continuing debate about the effects of other media on children.

\section{Storytelling through audio-visual media}

Several researchers have worked to know the effects of different media and as a result diverse theories were presented. The biggest concern regarding media effects might be the assessment of negativity and positivity of distinct media. Children are identified as the vulnerable audience for sundry mass media. A very important research project in this regard is Payne Fund Studies that were conducted to apprehend the effects of films on children in $1928 .{ }^{17}$ After that, doors opened for a number of studies and theories related to the same grounds.

Various debates have taken place to discuss the pros and cons on the effect of each medium in children's progress and their life development. But a lesser amount of research exists about the comparison between audio and audio-visual media. Whereas, communication for developmental process can be seen from ancient Indian fables of 'Panchatantra' to the persuading television programs like Sesame Street for beginners. The medium that might have proved itself as one of the most influential mode of communication over the time is television.

Many studies during 1970s and 80s highlight that auditory attention and visual attention are positively correlated with each other. Visual attention enhances if children are able to comprehend the content of any television program. ${ }^{18}$ Auditory and audio-visual content can be grasped well than visual content alone on the comprehension tests. ${ }^{19}$

A number of researchers believe that educational television has a positive impact on cognitive development of children. ${ }^{20}$ Recent researchers support the idea that children get influenced positively by the media if the content is prosocial. ${ }^{21}$ Self-preference to watch

\footnotetext{
${ }^{17}$ Wartella, Ellen, and Byron Reeves. "Historical trends in research on children and the media: 1900-1960." Journal of Communication (Washington DC: Oxford University Press, 1985) 118-133.

${ }^{18}$ Alwitt, Linda F., Daniel R. Anderson, Elizabeth Pugzles Lorch, and Stephen R. Levin. "Preschool children's visual attention to attributes of television." Human Communication Research (Delaware: Willey-Blackwell, 1980) 52-67.

${ }^{19}$ Field, Diane E., and Daniel R. Anderson. "Instruction and modality effects on children's television attention and comprehension." Journal of Educational Psychology (Arizona: American Psychological Association, 1985) 91.

${ }^{20}$ Lorch, Elizabeth Pugzles, and Daniel R. Anderson. "The relationship of visual attention to children's comprehension of television." Child Development (Medford: Wiley-Blackwell, 1979) 722-727.

${ }^{21}$ Mares, Marie-Louise, and Emory Woodard. "Positive effects of television on children's social interactions: A meta-analysis." Media Psychology (Washington DC: Taylor \& Francis, 2005) 301-322.
} 
prosocial content also matters as much as self-choice to violent content exposure. ${ }^{22}$ Both of them are found to be equally effective almost but in different directions. ${ }^{23}$

Attention-grabbing content is the key to persuade learning among under-privileged children. Programs such as Blue's Clues and Sesame Street, and cartoons like Dora the Explorer engage children because of its strong script. ${ }^{24}$

Bryant and Anderson ${ }^{25}$, Singer and Singer $^{26}$ and many other theorists during $1980 \mathrm{~s}$ presented a relatively diverse theory of television viewing. They suggested that watching any program on television is an active phenomenon that involves our attention and actively engages our senses. Crawley et al. ${ }^{27}$ looked into the effects of repeated exposure on the viewing behaviours and perception of preschool children and found out that verbal and nonverbal interactions increased with repetition. "Blue's Clues" (a television series intended to enhance critical thinking and cognitive skills in young children) was shown to young children and it was noticed after videotaping their behaviour that their verbal and nonverbal interactions got improved and comprehension enhanced with recurrence. However, only 5 year old boys had somewhat different findings.

Anderson et al. ${ }^{28}$ held the same view by referring their longitudinal study comparing children who watched the same educational program on a regular basis to children who did not watch this series. They concluded that the said program had a positive impact on cognitive development. The educational television programming largely focuses on cartoon characters to target the children. Amna, a kindergarten teacher, remembers how television cartoons had a positive impact on her character building, "A positive attitude and friendly conduct brings you closer to people and you make friends while if you are a bully or bad guy, people would stay at a distance from you and would not want to be your friend." But the question remains same, 'is exposure to television enough to inculcate the same cognitive learning a child might have from story books?'

${ }^{22}$ Ennemoser, Marco, and Wolfgang Schneider. "Relations of television viewing and reading: Findings from a 4-year longitudinal study." Journal of Educational Psychology (Arizona: American Psychological Association, 2007) 349.

${ }^{23}$ De Leeuw, Rebecca NH, Mariska Kleemans, Esther Rozendaal, Doeschka J. Anschütz, and Moniek Buijzen. "The impact of prosocial television news on children's prosocial behavior: An experimental study in the Netherlands." Journal of children and media (New Jersey: EBSCO Publishing, 2015) 419-434.

${ }^{24}$ Kirkorian, Heather L., Tiffany A. Pempek, Lauren A. Murphy, Marie E. Schmidt, and Daniel R. Anderson. "The impact of background television on parent-child interaction." Child development (Medford: WileyBlackwell, 2009) 1350-1359.

${ }^{25}$ Bryant, Jennings, and Daniel R. Anderson. Children's understanding of television: Research on attention and comprehension. (New York: Academic Press, 1983).

${ }^{26}$ Singer, Jerome L., and Dorothy G. Singer. "Psychologists look at television: Cognitive, developmental, personality, and social policy implications." American Psychologist (Arizona: American Psychological Association, 1983) 826.

${ }^{27}$ Crawley, Alisha M., Daniel R. Anderson, Alice Wilder, Marsha Williams, and Angela Santomero. "Effects of repeated exposures to a single episode of the television program Blue's Clues on the viewing behaviors and comprehension of preschool children." Journal of educational psychology (Arizona: American Psychological Association, 1999) 630.

${ }^{28}$ Anderson, Daniel R., Jennings Bryant, Alice Wilder, Angela Santomero, Marsha Williams, and Alisha M. Crawley. "Researching Blue's Clues: Viewing behavior and impact." Media psychology (Washington DC: Taylor \& Francis, 2000) 179-194. 
Another school of thought points out that it is not the medium but the message which actually plays a significant role in learning. Any one particular medium cannot be exclusively efficacious to provide instructional learning in terms of enhancing cognizance. Television as a medium should not be blamed because of the content broadcasted on it. Books also feature the fantasy content at large, so the effects of content must be scrutinized instead of the medium. Kendeou et al. ${ }^{29}$ particularly studied the role of television viewing and listening in developing narrative comprehension and reading skills. They focused on the importance of early childhood education in the light of several research findings and claimed that comprehension skills develop at an early age and are not specific to the medium in which message is being provided. In contrast of McLuhan's famous phrase "Medium is the message", they argued that comprehension skills remain parallel across diverse media. Children interpret content through different media in almost similar ways. Inference generation has the main role in children's perception rather than the source of media. ${ }^{30}$

\section{Current scenario in Pakistan}

Television has become the most popular medium for the urban class for the last three decades. Majority prefer to tune in cartoon channels for their children. Life is becoming accelerated day by day in the cities of Pakistan. Because of the increasing rate of inflation, housewives now prefer to play the role of working women to run their houses. In this scenario, it is an easier solution to let children sit in front of television for hours. Additionally, now more and more married couples prefer living separate from their parents, therefore the concept of listening stories from grandparents is gradually fading out. If we evaluate this inclination with the past decades, more time used to be spent in story telling as compared to television watching. These both trends might have different effects on children's minds and habits. Time will probably tell the consequences of the exposure to both forms of communication, verbal and electronic, in the lives of children.

\section{Present Study}

The primary aim of this research was to identify the ratio of each medium designated in the lives of children to develop a positive personality and to determine media effects on children's vocabulary and perception. Through this study parents, school authorities and media analysts would be capable to identify the role of both media on children's cognitive skills. This study is beneficial for the future researchers belonging to the different disciplines of social sciences such as mass communication, psychology, sociology, linguistics and education.

\section{Research Questions}

This study addressed three questions:

\footnotetext{
${ }^{29}$ Kendeou, Panayiota, Julie S. Lynch, Paul Van Den Broek, Chris A. Espin, Mary Jane White, and Kathleen E. Kremer. "Developing successful readers: Building early comprehension skills through television viewing and listening." Early Childhood Education Journal (Pennsylvania: Springer, 2005) 91-98.

${ }^{30}$ Spence, Kenneth W., and Janet Taylor Spence. Psychology of learning and motivation. (New York: Academic Press, 1967) 244- 248
} 
RQ1: What are the major differences in the comprehension and cognition of children who watch stories on television and those who listen stories in their routine lives?

RQ2: How much is the effect/power of the message of single (listening) and multiple (listening and watching) senses (i.e. to measure the potency of each medium).

RQ3: What is the effect of each medium on children's vocabulary and language skills?

\section{Hypotheses}

On the basis of above research questions, following problem is analysed:

Is story listening in traditional settings more effective than cartoon watching in terms of cognitive learning? Accordingly, the following hypotheses are designed:

$\mathrm{H}_{1}$ : Children who listen stories have stronger vocabulary than those who watch cartoons.

$\mathrm{H}_{2}$ : Children who listen stories have a better comprehension and understanding of message than those who watch cartoons.

\section{Method}

\section{Participants}

The study was conducted with a sample of 100 girls and 100 boys aged from 7 to 12 years. This particular age group was selected so that children could respond properly as according to Piaget's theory of cognitive development, concepts become tangible and specific in this age. The participants were chosen from four different schools of Karachi, Pakistan. These schools were selected on the basis of some primary characteristics. All schools were charity-based organizations located in the slum areas of Karachi. All students were belonged to low socio-economic status. Specifically those children were included in the study whose monthly household income was less than $200 \$$. None of the participants had listened or watched the stories earlier. After stratifying these basic criteria, only four schools were selected through random sampling, as a limited number of participants are required to conduct experimental studies.

\section{Design}

50 children from each school initially participated in the study. Experimenter assigned them to two groups on the basis of the medium they were exposed to. Group 1 listened the stories from an elderly female figure, whereas Group 2 watched the same stories on television in the form of cartoon movies. Medium was the independent variable in the study which had two sub-groups, story listening and cartoon watching whereas vocabulary and comprehension were the dependent variables. Control variables were message (content), laboratories' environment, economic background of children (low socio-economic), location (Karachi, Pakistan) and time period (10 weeks).

\section{Stimulus Materials}

The content selected for this experiment was "Meena's Stories" in Urdu language available in both forms, books and DVDs. Meena is a fictional character, conceived by 
UNICEF in September 1998 after a comprehensive research of eight years on South Asian region. First 10 stories were selected out of more than 30 episodes of Meena series (See Figure 1: Experimental Design).

\section{Experimental Design}

\begin{tabular}{|c|c|}
\hline \multicolumn{2}{|c|}{ Sample } \\
\hline \multicolumn{2}{|c|}{200 Children } \\
\hline \multicolumn{2}{|c|}{ Age } \\
\hline \multicolumn{2}{|c|}{7 to 12} \\
\hline \multicolumn{2}{|c|}{ Gender } \\
\hline $\begin{array}{c}\text { Group } 1 \\
50 \text { girls and } 50 \text { boys }\end{array}$ & $\begin{array}{c}\text { Group } 2 \\
50 \text { girls and } 50 \text { boys }\end{array}$ \\
\hline \multicolumn{2}{|c|}{ Medium } \\
\hline $\begin{array}{c}\text { Group } 1 \\
\text { Stories (listened by an adult) }\end{array}$ & $\begin{array}{c}\text { Group 2 } \\
\text { Cartoons (watched on TV) }\end{array}$ \\
\hline \multicolumn{2}{|c|}{ 1- Count your chickens } \\
\hline \multicolumn{2}{|c|}{ 2- Dividing the mango } \\
\hline \multicolumn{2}{|c|}{ 3- Say no to dowry } \\
\hline \multicolumn{2}{|c|}{ 4- Take care of girls } \\
\hline \multicolumn{2}{|c|}{ 5- Saving a life } \\
\hline \multicolumn{2}{|c|}{ 6- Who is afraid of the bully? } \\
\hline \multicolumn{2}{|c|}{ 7- Will Meena leave school? } \\
\hline \multicolumn{2}{|c|}{ 8- Meena's three wishes } \\
\hline \multirow{2}{*}{\multicolumn{2}{|c|}{ 9- Too young to marry }} \\
\hline & ool \\
\hline
\end{tabular}

Fig 1: Experimental Design adopted in the study

\section{Procedure}

Four schools participated in the study. In each school, the experiment was conducted simultaneously in two classrooms of almost same dimensions (20' by $30^{\prime}$ ). Each session was comprised of two conditions. In one class, an aged female (57 years) told one story at a time to group 1 for ten consecutive weeks. In the other room, children from group 2 watched the cartoons of the similar content at the same time for an equal period. A group of 30 students at a time was taken to one of the rooms by an experimenter (an aged female) where they listened 1 story at a time for ten consecutive weeks. These all subgroups were named as group 1 communally. The other half children, designated as group 2 were taken to a different room by another experimenter in groups of 30 students at a time. They watched the same stories on a television screen ( 24 inches LED) in the form of cartoons for almost equal duration. This screen was carried by the experimenter in each session.

In each of the experimental conditions, children sat on a carpet by a distance of about 1 feet $(0.30 \mathrm{~m})$ from each other in a semi-circle either to listen stories or to watch 
television and then filled out the questionnaires separately by sitting on desks in another classroom. An attempt was made to create an environment for the children who listened stories, as if they were listening stories by some grandmother like figure at home. It was also tried to make sure that children who watched television would feel comfortable in the presence of fellow mates rather than sitting alone with the experimenter. In the verbal storytelling condition, children sat at a distance of about three feet $(0.91 \mathrm{~m})$ from the storyteller. In the visual storytelling condition, children assembled at a distance of about four feet $(1.21 \mathrm{~m})$ from the colored television screen positioned slightly above their eye level.

After conducting the pilot study on a separate group of 30 students, 15 in each group, some minor changes were made in the multiple-choice options like a few words were replaced with their simpler alternatives. Then actual study was initiated on alternative weekdays in different schools during the first three months of 2017. The exposure time for both conditions was almost similar with a minor difference of a few minutes in each episode. The usual length of each episode was from 11 to 12 minutes, except episode 8, "Meena's three wishes" which took only 8 minutes to get completed.

After the completion of each episode, children were immediately provided with the questionnaires. All questions were in Urdu. Each questionnaire contained questions related to the vocabulary used in each episode and about the perception linked with the theme of that particular episode. Room temperature was between 22 to $25^{\circ} \mathrm{C}$ during all experiments. Story teller tried her best to give vocal and facial expressions according to the dialogs and characters during narration. Outside noise and room lights were deliberately controlled in both conditions, so that students would not be disturbed by internal and external factors.

\section{Measures and Analyses}

The IBM Statistical Package for Social Sciences (SPSS), version 22 was used for data evaluation.

\section{Vocabulary Score}

Children's vocabulary score was measured by means of a multiple-choice test after each story. Each test contained 3 questions related to the vocabulary used in the content, with a total of 30 corresponding multiple-choice questions. The questionnaires asked the respondents to identify the correct meaning or synonyms of given words which were used somewhere in both verbal and televised versions. Each question had only one correct option. Cronbach's alpha (K-R 20) was 0.82 .

\section{Perception Score}

Children's perception score was also assessed by means of a multiple-choice test included in the same questionnaires. There were total 30 corresponding multiple-choice questions. The questions were included to estimate what children inferred from the story they either listened or watched and how they became cognizant of the message given to them in each session. Cronbach's alpha (K-R 20) was 0.83 . 


\section{Results}

\section{For Vocabulary Results}

A chi-square goodness-of-fit test was conducted between medium of message (viewing versus listening) and vocabulary score. All expected cell frequencies were greater than five. The results showed that medium of message (viewing versus listening) of the stories in our study has significantly differ from the hypothesized value. Listening the stories significantly increases the vocabulary score of the children as compare to viewing the stories in the form of animated cartoons (chi-square with 2 degrees of freedom $=$ $37.750, \mathrm{p}=0.05)$.

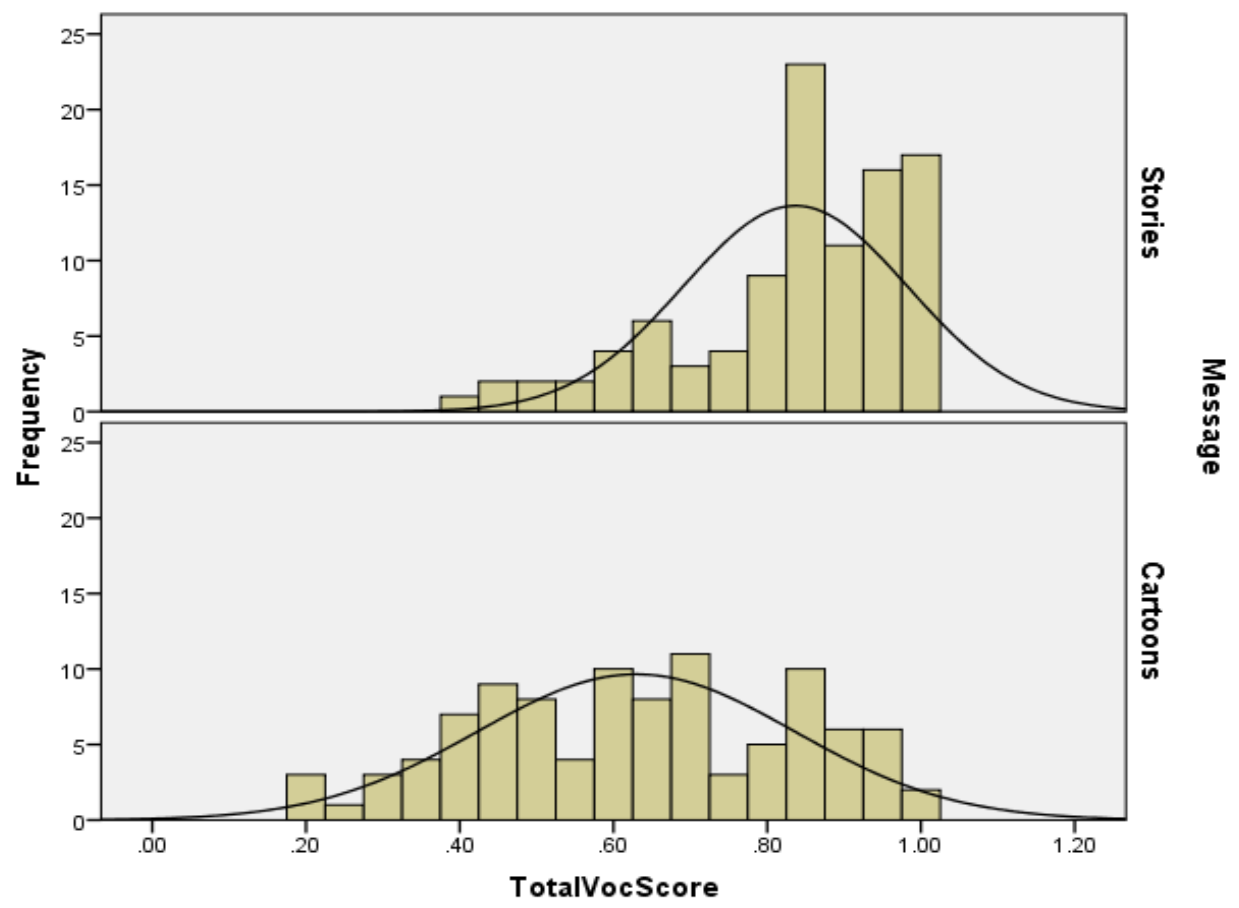

Fig 2: Comparison of vocabulary scores between listeners (Stories) and viewers (Cartoons)

For Perception Results

A $\chi^{2}$ goodness-of-fit test was conducted between medium of message (viewing versus listening) and vocabulary score. All expected cell frequencies were greater than five. The results showed that medium of message (viewing versus listening) of the stories in our study has significantly differ from the hypothesized value. Listening the stories 
significantly increases the vocabulary score of the children as compare to viewing the stories in the form of animated cartoons (chi-square with 2 degrees of freedom $=23.560$, $\mathrm{p}=0.01)$.

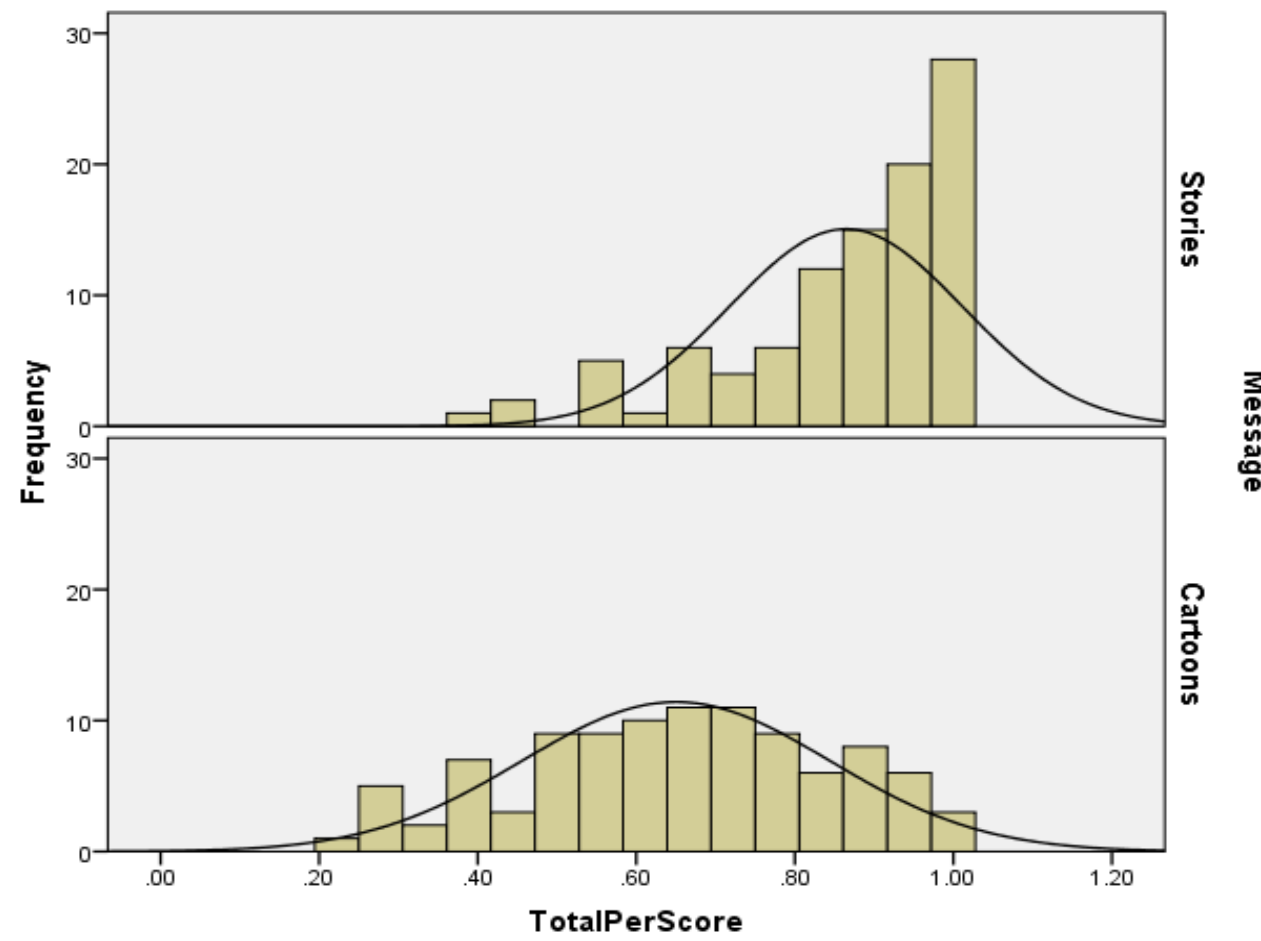

Fig 3: Comparison of perception scores between listeners (Stories) and viewers (Cartoons)

Significant differences can be perceived in group scores of children who listened stories by an adult and those who watched them on television. When the mean ranks were compared, it was identified that children who listened stories performed better on vocabulary as well as perception tests as compared to those who watched cartoons (See Table 1). 
Table: 1

Group Mean Scores for Vocabulary and Perception as a Function of Medium and Cognitive Skills

\begin{tabular}{|c|c|c|c|c|}
\hline & \multicolumn{4}{|c|}{ Cognitive Skills } \\
\hline & \multicolumn{2}{|c|}{ Vocabulary } & \multicolumn{2}{c|}{ Perception } \\
\hline Medium & $M$ & $S D$ & $M$ & $S D$ \\
\hline Stories (Audio) & 83.90 & 13.11 & 84.83 & 13.07 \\
\hline Cartoons (Video) & 66.67 & 18.34 & 67.37 & 16.51 \\
\hline$M$ & 75.28 & 18.10 & 76.10 & 17.24 \\
\hline
\end{tabular}

Taking everything into account, results affirmed both hypotheses which state that story listening is more effective than cartoon watching in terms of cognitive learning.

\section{Discussion}

The aim of this study was to observe the effects of giving message through different media on children's vocabulary and perception. Results proved that children who listened stories had better vocabulary than those who watched cartoons. Many factors can be involved in these findings. Several psychologists have worked on the learning aspect of media. Interaction with other people also plays a crucial role in building our own concepts. ${ }^{31}$ It can be concluded that our concepts are an amalgamation of selfexperiences and interaction with other people. ${ }^{32}$

In story telling sessions, a motherly figure, who told stories to children might have had played a significant role. These sessions were interactive and children asked different questions related to stories during narration. An explanation was given to them each and every time. Hovland and Weiss ${ }^{33}$ mentioned that source (who) is of great importance by whom any message is delivered. If the messenger is trustworthy, then a large number of people would follow the message. The personality of a communicator plays a major role in persuading the audience. Her/his physical appearance and social aspects might be responsible whether a receiver would be able persuaded by the message or not. The second important point is the relationship between the communicator and listener. The third and last condition is the context of that situation in which message is given.

\footnotetext{
${ }^{31}$ Manis, Jerome G., Bernard N. Meltzer, and Jerome G. Manis. Symbolic interaction: A reader in social psychology. Boston: Allyn and Bacon, 1972.

${ }^{32}$ Mead, George Herbert. "George Herbert Mead. 1934. Mind, Self, and Society from the Standpoint of a Social Behaviorist, edited by Charles W. Morris. Chicago: University of Chicago, selected 68-75." (2014): 42-47.

${ }^{33}$ Hovland, Carl I., and Walter Weiss. "The influence of source credibility on communication effectiveness." Public opinion quarterly 15, no. 4 (1951): 635-650.
} 
Environmental factors, personal bonding and the venue where communication is taking place are of great importance that can be resulted in positive and negative responses. ${ }^{34}$

Another idea presented by linguistics theorists is of "expansions". Adults especially parents assist children to expand their vocabulary and improve their language skills. Child utters only two to three words at an early age to express any idea. They are adults who continue to enrich their expressions and language structure by providing them with grammatically correct forms of sentences. Similarly, a notion known as "motherese" is used to define the ways mothers use to interact with her child. Usage of proper reorganized sentences, repetitive melodious words and encouraging interaction with mother ensure that child learn about language in a better way. Attachment styles are a huge promoter to determine emotional and social contexts. ${ }^{35}$ Jung believed that 'mother archetype' is a core archetype that has a great influence on children's life. It is the core bond that children form at an early age. This archetype lead them towards empathetic figures. Mother's archetype is discussed by several theorists in childhood development. One of the early theories focusing on child-mother relationship is object relations theory. The concept of this theory was initially developed by Abraham ${ }^{36}$ but it has modifications by different theorists till date. Contrary to the Freud's viewpoint of "Oedipus" and "Electra" complexes for same-sex parents, this theory argues about the internal satisfaction and gratification children have by the close bond with parents specifically with their mothers. Infants react to their mothers more often by showing happiness or anger to them than other adults. Thus, motherly figures are the main source of building association with children.

If we analyse the results of second group who watched television, we can infer that they have relatively lower scores on vocabulary and perception tests. One reason might have been that children who watched televised episodes did not have an opportunity to interact with or ask questions from some elderly one. In live reading, speakers use gestures in both conditions and they are helpful in enhancing their communication and interaction ability. On the other hand, cool media like television have no direct links with their audiences. ${ }^{37}$ George Gerbner ${ }^{38}$ mentioned different assumptions related to the television content in his cultivation theory. He declared that television is a totally different medium as compared to other mass media. He stressed that its contribution for the betterment of society is somehow lesser relatively to other media. Print has a positive impact on learning effectiveness whereas television has mostly negative effects.

\footnotetext{
${ }^{34}$ Burgoon, Michael, Stephen B. Jones, and Diane Stewart. "Toward a Message-Centered Theory of Persuasion: Three Empirical Investigations of Language Intensity1." Human Communication Research 1, no. 3 (1975): 240256.

${ }^{35}$ Seay, Billy, Ernst Hansen, and Harry F. Harlow. "Mother-infant separation in monkeys." Journal of Child Psychology and Psychiatry (London: Wiley-Blackwell, 1962) 123-132.

${ }_{36}$ Abraham, Karl. "Character-formation on the genital level of libido-development." The International Journal of Psycho-Analysis (New York: Taylor \& Francis, 1926) 214.

${ }^{37}$ Alibali, Martha W., Dana C. Heath, and Heather J. Myers. "Effects of visibility between speaker and listener on gesture production: Some gestures are meant to be seen." Journal of Memory and Language (New York: Elsevier, 2001) 169-188.

${ }^{38}$ Gerbner, George, Larry Gross, Michael Morgan, and Nancy Signorielli. "Living with television: The dynamics of the cultivation process." Perspectives on media effects (New Jersey: Lawrence Erlbaum Associates, 1986) 17-40.
} 
If we compare both media, then results support the idea that children who learn from stories possess better cognitive skills then those who are exposed to television. McLuhan devised the phrase, "the medium is the message". He held the view that the source of any content decides the nature and importance of that message. ${ }^{39}$ It can be concluded that it might be the medium, not the message which matters what a child may infer from it.

McLuhan classified mass media into two different categories and named them as "hot media" and "cool media". He considered print media as hot media, as they provide everything in detail so our mind becomes less involved during the exposure. On the other hand, our minds are more engaged in the communication process through electronic media. The later provides less information and demands more participation, thus was denoted them as cool media. Some researchers defend that television viewing is not a passive, but an active pastime for young children. ${ }^{40}$ Although reading may entail more cognitive concentration but people feel relaxed and satisfied during both activities. ${ }^{41}$ Comprehension from television is a very demanding phenomenon in the case of young children $^{42}$ and television viewing is not considered an easier activity across all cultures. ${ }^{43}$

Nevertheless, most of the studies uphold the view that television viewing is a passive activity with negligible cognitive involvement. Comparatively lesser amount of mental effort is required to grasp information from television as compared to books. Television influences reading habits of children in a destructive manner and the association of television viewing with academic achievement is mostly negative. ${ }^{44}$

Many researchers highlighted the significance of storytelling in establishing communication between parents and children by stating that story narrations develop an emotional bond that results in enhancing better communication skills. Parents, teachers and regulatory bodies can play pivotal role in disseminating media literacy among children. ${ }^{45}$ Several studies declare that mediation has the core importance in this regard. It also depends on the parents' self-beliefs about child caring and their active involvement in nurturing their children, which do not always seem palpable. The time might have been come to ponder upon revitalizing the tradition of storytelling for the better cognitive development of children.

\footnotetext{
${ }^{39}$ Goodman, Joanna, and Catherine Truss. "The medium and the message: communicating effectively during a major change initiative." Journal of Change Management (Abingdon: Routledge, 2004) 217-228.

${ }^{40}$ Beentjes, Johannes WJ, and Tom HA Van der Voort. "Television's impact on children's reading skills: A review of research." Reading research quarterly (New York: Wiley-Blackwell, 1988) 389-413.

${ }^{41}$ Csikszentmihalyi, Mihaly, and Robert Kubey. "Television and the rest of life: A systematic comparison of subjective experience." Public Opinion Quarterly (New Jersey: Oxford University Press, 1981) 317-328.

${ }^{42}$ Huston, Aletha C., John C. Wright, Janet Marquis, and Samuel B. Green. "How young children spend their time: television and other activities." Developmental psychology (London: Wiley-Blackwell, 1999) 912.

${ }^{43}$ Anderson, Daniel R., and Katherine G. Hanson. "From blooming, buzzing confusion to media literacy: The early development of television viewing." Developmental Review (New York: Elsevier, 2010) 239-255.

${ }^{44}$ Williams, Patricia A., Edward H. Haertel, Geneva D. Haertel, and Herbert J. Walberg. "The impact of leisuretime television on school learning: A research synthesis." American educational research journal (Los Angeles: Sage Publications, 1982) 19-50.

${ }^{45}$ Zimmerman, Frederick J., Dimitri A. Christakis, and Andrew N. Meltzoff. "Associations between media viewing and language development in children under age 2 years." The Journal of pediatrics (Illinois: Elsevier, 2007) 364-368.
} 


\section{Conclusion}

The study supports the idea that regardless of the message, the medium seems to be of more worth in determining learning skills of children from media. Oral (single sensory) learning might have proved to be more powerful than visual (multiple sensory) learning in terms of cognitive development.

In the comparison of hot media (audio stories) and cold media (television), children who listened stories performed better in both vocabulary and perception tasks. The main reasons include the active participation of children in story telling sessions, whereas television viewing was observed to be a passive activity during experiment. The role of narrator holds a significant role as children listened the message more carefully when the speaker communicated directly to the audience. Non-verbal gestures such as facial and vocal expressions might also play a major role in making the message more comprehensible.

All in all, by this experimental study, storytelling proved to be a very healthy activity in enhancing children's vocabulary and making their perception better towards messages given in each story. So it can be concluded that listening of stories from a narrator is more helpful than watching them on television for improving children's cognitive abilities. It is the time to revive the old tradition of storytelling at homes, if we want to make the children more talented in terms of communicative and perceptive skills. 